\title{
High performance of sensorless sliding mode control of doubly fed induction motor associated with two multilevel inverters fed by VFDPC_SVM rectifier
}

\author{
Djamila Cherifi ${ }^{1}$, Yahia Miloud ${ }^{2}$ \\ ${ }^{1,2}$ GACA Laboratory, Department of Electrical Engineering, Faculty of Technology, University of Dr Moulay \\ Tahar, Saida, Algeria
}

\begin{tabular}{l} 
Article Info \\
Article historys: \\
Received Aug 5, 2019 \\
Revised Jun 5, 2020 \\
Accepted Jun 24, 2020 \\
\hline Keywords: \\
Doubly fed induction motor, \\
Sliding mode observer, \\
Three-level inverter, \\
PWM rectifier; \\
Direct power control (DPC), \\
Space vector modulation \\
(SVM), \\
Virtual flux
\end{tabular}

\begin{abstract}
The purpose of this paper is to develop a robust sensorless control based on the sliding-mode observer applied to a doubly fed induction motor associated with two three-level NPC-type voltage inverters fed by PWM rectifier. In this context, the authors propose in the first part, and after the presentation of the model of three-level NPC-type voltage inverters, this type of inverter has several advantages over the standard two-level inverter, such as a greater number of levels in the output waveforms, give less harmonic distortion in voltage and current waveforms and lower switching frequencies. They also present the control strategy of three-phase pulse width modulation rectifier. They propose the virtual flux-based direct power control (DPC_VF) with vector modulation (SVM). This method is applied for the enhancement of network power quality by compensation of harmonic currents produced by a non-linear load, and good regulation of DC-bus voltage. The second part of the paper is dedicated to the presentation of the robust observer for sensorless speed control of doubly fed induction motor (DFIM), based on the sliding mode. Simulation results of this proposed system were analyzed using MATLAB environment.
\end{abstract}

\section{Corresponding Author:}

Djamila Cherifi,

Department of Electrical Engineering,

University of Dr Moulay Tahar,

Saida, 20000. Algeria.

Email: d_cherifi@yahoo.fr

\section{INTRODUCTION}

Variable speed electric drives have gained considerable importance in industry and research over the last decade and require multidisciplinary knowledge in the field of electrical engineering such as: electrical machines, power electronics, electronics computer science, programmable technologies and the theory of dynamic systems control. Recent developments in these disciplines have made it possible to develop very high performance control systems [1].

The Doubly Fed Induction Machine (DFIM) is highly popular since it has certain advantages over all other types of AC machines. This machine has experienced particular growth in recent years, either in the electromechanical conversion chain with variable speed, as a motor for certain industrial applications (Rail traction, marine propulsion and pumping), or as a generator for electrical energy production (wind energy etc) [2]. Indeed, the DFIM has been widely used because of its high efficiency, energy quality, robustness. Another reason for the selection of this machine is due to the degrees of freedom it offers because of the accessibility of its rotor. Therefore, the possibility of feeding it by a converter on both the stator side and the rotor side, and 
also a widening of the speed range (hypo-synchronous, hyper-synchronous). However, the control of the DFIM can be highly complex depending on the desired performance. This complexity is mainly due to the analytical model of the machine is non-linear, multi-variable, strongly coupled and very sensitive to variations in internal parameters and external disturbances [3], [4]. To solve this problem, several control algorithms of DFIM have been developed in the literature to improve its performance, robustness and stability. In this context, the Field Oriented Control (FOC) has been developed to ensure decoupling between the flux and the electromagnetic torque of the DFIM. This decoupling provides a fast torque response, wide speed control range and high efficiency for a wide load variation range. But, the knowledge of the rotor speed is necessary, and requires additional speed sensor on the machine which adds to the cost and the complexity of the drive system. In this regard, sensorless vector control has received much attention in induction motor drives and became in recent years, not only a track of research, but also a business challenge for industrial. In recent literature, many researches have been carried on the design of sensorless control schemes. The advantages of speed sensorless induction motor drives are the reduction of hardware complexity and lower cost, the reduction size of the drive machine, elimination of the sensor cable, better noise immunity, increased reliability and less maintenance requirements. Several strategies have been proposed in the literature to address this issue [5], [6], [7]. Due to the important properties of variable structure systems, we propose in this work an observer based on the sliding mode approach. However, the Field Oriented Control (FOC) also has a high sensitivity to parametric variations in the machine. This classical technique use speed regulation based Proportional Integral (PI) controllers. The use of conventional speed controllers does not provide a good performance when the set point varies. Faced with this drawback, this work proposes a robust adjustment technique based on the sliding mode controller.

Inverters are widely used in various industrial applications such as variable speed drives system because of their ability to control the magnitude and frequency of the output voltage. Recently, to reduce the harmonics in the inverter output voltage and to meet the voltage rating of the power devices the multi-level structures are used. Multilevel inverters have been more advantages, due to its performance like power ratings, improved harmonic performance [8], [9]. The multilevel inverter consists of three topologies, and we are proposing in this work the NPC three-level inverter for DFIM-supply.

PWM rectifier has the advantage of low net side current harmonic, unit power factor, bidirectional energy flow and constant dc voltage control. There are many types of PWM rectifier control strategy, including direct power control strategy, its superiority is fast track power, power factor is high, the structure and the algorithm is simple, fast dynamic response [10], [11]. Generally, there are two types of DPC technique: voltage based DPC (VDPC) and virtual flux based DPC (VF DPC) [12], [13]. This paper puts forward a kind of three-phase PWM rectifier direct power control strategy which is based on virtual flux control.

According to the authors' knowledge, no work has been reported on the application of the three-level inverter fed by PWM rectifier system as DC source input for sensorless control for a doubly fed induction machine operating in motor mode

The main contributions of this work are:

- Improve the performance and robustness of sensorless control of doubly fed induction motor facing to the load torque and speed variation.

- Synthesize a robust control based on a sliding mode controller is developed to improve the dynamic speed response of DFIM.

- Application of the three-level inverter fed by PWM rectifier system as DC source input, this method is applied for the enhancement of network power quality by compensation of harmonic currents produced by a non-linear load, and good regulation of DC-bus voltage.

\section{DOUBLY FED INDUCTION MOTOR MODEL}

A dynamic model of the doubly fed induction motor in stationary reference frame can be expressed by:

$$
\left\{\begin{array}{l}
\frac{d}{d t} i_{s d}=-\lambda i_{s d}+\omega_{s} i_{s q}+\frac{K}{T_{r}} \phi_{r d}+\omega \cdot K \phi_{r q}+\frac{1}{\sigma L_{s}} v_{s d}-K v_{r d} \\
\frac{d}{d t} i_{s q}=-\omega_{s} i_{s q}-\lambda i_{s q}-\omega \cdot K \phi_{r d}+\frac{K}{T_{r}} \phi_{r q}+\frac{1}{\sigma L_{s}} v_{s q}-K v_{r q} \\
\frac{d}{d t} \phi_{r d}=\frac{L_{m}}{T_{r}} i_{s d}-\frac{1}{T_{r}} \phi_{r d}+\omega \cdot \phi_{q r}+v_{r d} \\
\frac{d}{d t} \phi_{r q}=\frac{L_{m}}{T_{r}} i_{s q}-\omega \cdot \phi_{r d}-\frac{1}{T_{r}} \phi_{r q}+v_{r q} \\
\frac{d}{d t} \omega=p^{2} \frac{L_{m}}{L_{r}}\left(\phi_{r d} i_{s q}-\phi_{r q} i_{s d}\right)-\frac{f}{J} \omega-\frac{C_{r}}{J}
\end{array}\right.
$$

with: 


$$
T_{r}=\frac{L_{r}}{R_{r}} ; T_{s}=\frac{L_{s}}{R_{s}} ; \lambda=\frac{1}{\sigma . T_{r}} ; K=\frac{L_{m}}{\sigma L_{s} L_{r}} ; \quad \sigma=1-\frac{L_{m}^{2}}{L_{s} L_{r}} ; \quad \omega=p . \Omega
$$

The electromagnetic torque is expressed by:

$$
T_{e m}=\frac{p L_{m}}{L_{r}}\left(\phi_{r d} \cdot i_{s q}-\phi_{r q} \cdot i_{s d}\right)
$$

\section{THREE LEVEL NPC INVERTER}

With the increasing popularity of multi-level inverters, the room for improvement of the performance of voltage source inverters has continuously been tested for various applications [15], [16], [17]. The threelevel NPC VSI, presented in Figure 1, is one of the most commonly applied multilevel topologies.

The three level NPC topology consist of 12 switches including 6 diodes. It is necessary to connect two capacitors in series both charged with $V_{\mathrm{dc}}$. Each phase led contains 4 series switches with two diodes clamped in series. The main function of the diodes is to clamp the upper switches at higher potential to the zero dc-link point. A particular switching pattern will give the output of three level NPC inverter. The circuit diagram shown in Figure 1 gives idea about the arrangement of the power circuit required for the three level NPC inverter. In this circuit, the diodes are arranged in such a way that it yields different stages of voltages with respect to neutral point $\mathrm{N}$. The splitting of the voltage level is considered according capacitors $\mathrm{C}_{1}$ and $\mathrm{C}_{2}$ arranged in series with each other having neutral point $\mathrm{N}$ in between them. The division of voltages are obtained as $\mathrm{V}_{\mathrm{dc}} / 2,0,-\mathrm{V}_{\mathrm{dc}} / 2$. So it is named as three level topology.

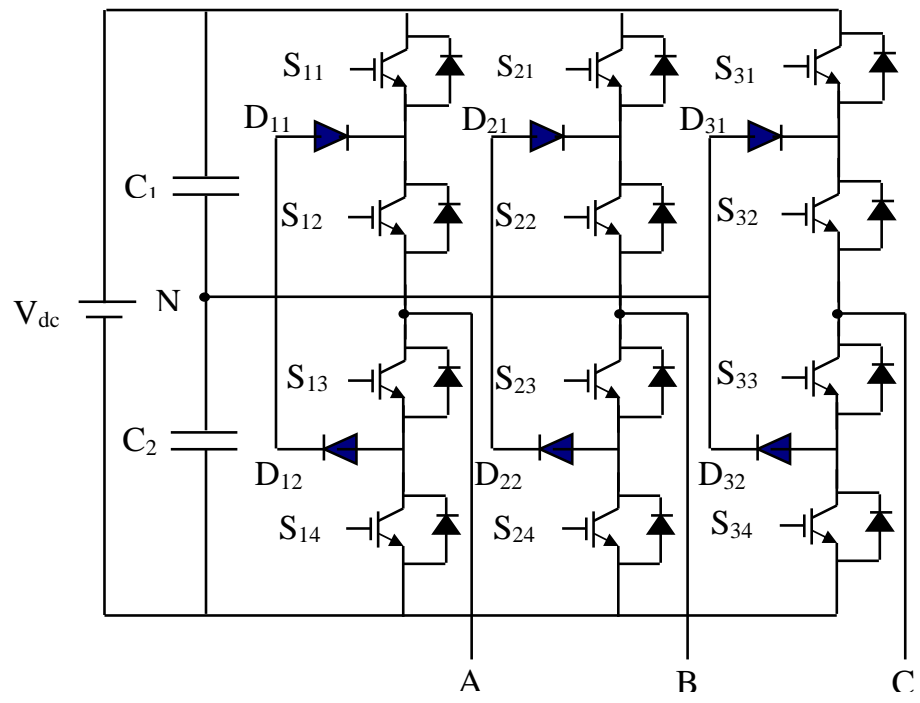

Figure 1. Three level NPC inverter

\section{DIRECT POWER CONTROL STRATEGY}

The presence of harmonics in the electrical network is one of the important phenomena causing the degradation of the quality of the energy, more particularly the deformation or the distortion of the voltage wave, [18]. One of the interesting solutions for harmonic reduction is the use of a PWM rectifier, [19].

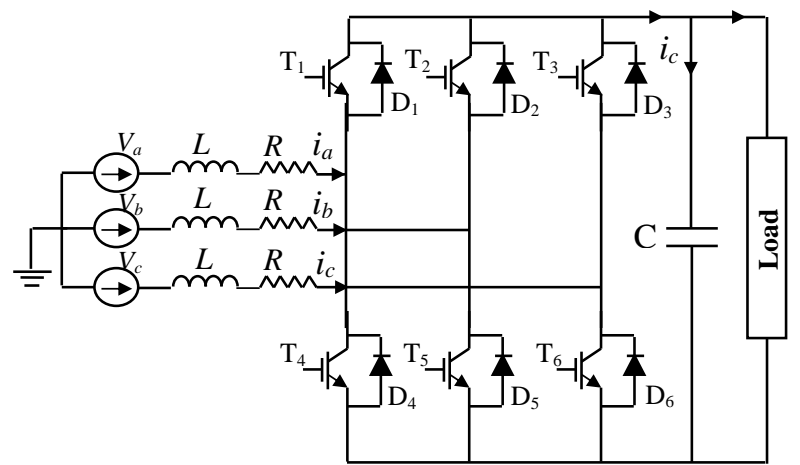

Figure 2. Topology of three-phase PWM rectifier

Over the years, alternative strategies have been proposed in the literature for the control of the PWM three-phase voltage rectifier, among them Direct Power Control (DPC), this command is developed by analogy 
with the direct torque control (DTC) of induction motors. It consists in controlling the instantaneous, active and reactive powers, instead of the torque and flux through two internal loops, [20], [21]. In this work, we are interested in the virtual flux-based direct control (DPC_VF) with vector modulation (SVM). This control strategy provides a high power factor and a quasi-sinusoidal waveform of the currents absorbed with a low THD while keeping the advantage of a control without line voltage sensor. The structure of the DPC_VF with vector modulation (SVM) is given by Figure 3.

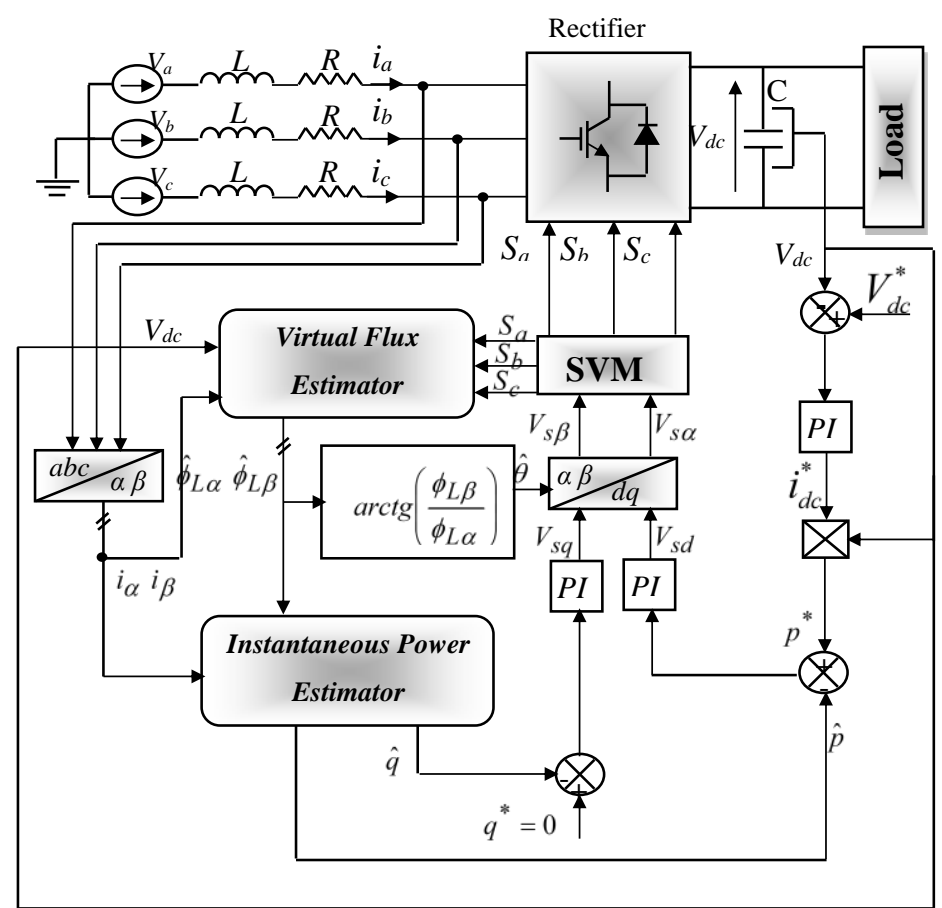

Figure 3. Structure of the DPC_VF with vector modulation (SVM)

The components of the virtual flux are calculated from the following equations, [22]:

$$
\begin{aligned}
& \hat{\phi}_{L \alpha}=\int\left(u_{s \alpha}+L \frac{d i_{\alpha}}{d t}\right) d t \\
& \hat{\phi}_{L \beta}=\int\left(u_{s \beta}+L \frac{d i_{\beta}}{d t}\right) d t
\end{aligned}
$$

We can write:

$$
\begin{aligned}
& \hat{\phi}_{L \alpha}=L . i_{\alpha}+\int u_{s \alpha} d t \\
& \hat{\phi}_{L \beta}=L . i_{\beta}+\int u_{s \beta} d t
\end{aligned}
$$

Estimation of the instantaneous power based on the virtual flux, [19]:

$$
\begin{gathered}
\bar{\phi}_{L}=\left[\begin{array}{l}
\phi_{L \alpha} \\
\phi_{L \beta}
\end{array}\right]=\left[\begin{array}{l}
\int e_{\alpha} \\
\int e_{\beta}
\end{array}\right] \\
\bar{\phi}_{c}=\left[\begin{array}{c}
\phi_{s \alpha} \\
\phi_{s \beta}
\end{array}\right]=\left[\begin{array}{l}
\int u_{s \alpha} \\
\int u_{s \beta}
\end{array}\right]
\end{gathered}
$$

The voltage equation is written in the following form, [23]:

$$
\bar{e}=R \bar{i}+\frac{d}{d t}\left(L \bar{i}+\bar{\phi}_{c}\right)
$$

In practice, the resistance $\boldsymbol{R}$ can be neglected, which gives

$$
\bar{e}=\frac{d}{d t}\left(L \bar{i}+\bar{\phi}_{c}\right)
$$

Using complex notation, instantaneous powers can be calculated as follows, [23]:

$$
p=\operatorname{Re}\left(e . \bar{i}^{*}\right)
$$




$$
q=\operatorname{Im}\left(e \cdot \vec{i}^{*}\right)
$$

The line voltage can be expressed according to the virtual flux as follows, [23]:

$$
\bar{e}=\frac{d}{d t} \bar{\phi}_{L}=\frac{d}{d t}\left(\phi_{L} e^{j w t}\right)=\frac{d \phi_{L}}{d t} e^{j w t}+j w \phi_{L} e^{j w t}=\frac{d \phi_{L}}{d t} e^{j w t}+j w \bar{\phi}_{L}
$$

So the instantaneous active power is calculated by, [23]:

$$
\hat{p}=\frac{d \phi_{L d}}{d t} i_{d}+w \phi_{L d} i_{q}
$$

For a balanced three-phase sinusoidal voltage system, we have, [23]:

$$
\frac{d \phi_{L d}}{d t}=0 \Rightarrow \hat{p}=w \phi_{L d} i_{q}
$$

Which means that only the component of the current orthogonal to the flux vector that produces the instantaneous active power.

Similarly, the instantaneous reactive power can be calculated as follows, [23]:

$$
\begin{aligned}
\hat{q} & =-\frac{d \phi_{L d}}{d t} i_{q}+w \phi_{L d} i_{d} \\
\frac{d \phi_{L d}}{d t} & =0 \Rightarrow \hat{q}=w \phi_{L d} i_{d}
\end{aligned}
$$

The power estimator must use the quantities related to the stator $\alpha \beta$ :

$$
\begin{gathered}
\bar{e}=\left.\frac{d \phi_{L}}{d t}\right|_{\alpha}+\left.j \frac{d \phi_{L}}{d t}\right|_{\beta}+j w\left(\phi_{L \alpha}+j \phi_{L \beta}\right) \\
\bar{e} . \bar{i}^{*}=\left\{\left.\frac{d \phi_{L}}{d t}\right|_{\alpha}+\left.j \frac{d \phi_{L}}{d t}\right|_{\beta}+j w\left(\phi_{L \alpha}+j \phi_{L \beta}\right)\right\}\left(i_{\alpha}-j i_{\beta}\right)
\end{gathered}
$$

What allows to give, [23]:

$$
\begin{aligned}
& \hat{p}=\left.\frac{d \phi_{L}}{d t}\right|_{\alpha} i_{\alpha}+\left.\frac{d \phi_{L}}{d t}\right|_{\beta} . i_{\beta}+w\left(\phi_{L \alpha} i_{\beta}-\phi_{L \beta} i_{\alpha}\right) \\
& \hat{q}=-\left.\frac{d \phi_{L}}{d t}\right|_{\alpha} . i_{\beta}+\left.\frac{d \phi_{L}}{d t}\right|_{\beta} i_{\alpha}+w\left(\phi_{L \alpha} i_{\alpha}+\phi_{L \beta} i_{\beta}\right)
\end{aligned}
$$

For sinusoidal and balanced line voltages, the derivatives of the flux are zero. Instantaneous active and reactive powers are calculated as follows, [23]:

$$
\begin{gathered}
\hat{p}=w\left(\phi_{L_{\alpha}} i_{\beta}-\phi_{L_{\beta}} i_{\alpha}\right) \\
\hat{q}=w\left(\phi_{L_{\alpha}} i_{\alpha}+\phi_{L \beta} i_{\beta}\right)
\end{gathered}
$$

- Synthesis of PI controllers of active and reactive powers

The coefficients of the PI regulators of the power can be calculated by a simplified model of the rectifier in the reference $(\mathrm{d}, \mathrm{q})$.

The model in the referential $(\mathrm{d}, \mathrm{q})$ is:

$$
\left\{\begin{array}{l}
e_{d}=R \cdot i_{d}+L \cdot \frac{d i_{d}}{d t}-w \cdot L \cdot i_{q}+u_{s d} \\
e_{q}=R \cdot i_{q}+L \cdot \frac{d i_{q}}{d t}-w \cdot L \cdot i_{q}+u_{s q}
\end{array}\right.
$$

The phase shift of the flux $\bar{\phi}_{L}$ and the voltage $\bar{e}$ is $\left(\frac{\pi}{2}\right)$, we will have, [24]:

$$
e_{d}=0, e_{q}=E=\sqrt{\frac{3}{2}} E_{m} \text { and } p=E . i_{q}, q=E . i_{d}
$$

Hence the equation (24) becomes:

$$
\begin{gathered}
0=R \cdot i_{d}+L \cdot \frac{d i_{d}}{d t}-w \cdot L \cdot i_{q}+u_{s d} \\
E=R \cdot i_{q}+L \cdot \frac{d i_{q}}{d t}-w \cdot L \cdot i_{q}+u_{s q}
\end{gathered}
$$


The voltage of the line is considered as a constant disturbance and will have to be compensated for by the integral part of the PI corrector.

The closed loop transfer function is given by

$$
H(s)=\frac{E\left(k_{p} s+k_{i}\right)}{L . s^{2}+\left(E . k_{p}+R\right) s+E . k_{i}}
$$

The transfer function of a closed loop second order system is given by:

$$
F(s)=\frac{1}{s^{2}+2 \xi \omega_{n} s+\omega_{n}^{2}}
$$

By identification we will have

$$
k_{p}=\frac{2 \cdot L \cdot \xi \cdot \omega_{n}-R}{E} \text { and } k_{i}=\frac{L \cdot \omega_{n}^{2}}{E}
$$

\section{VECTOR CONTROL BY DIRECT ROTOR FLUX ORIENTATION OF DFIM}

The main objective of the vector control of DFIM is as in DC machines, to independently control the torque and the flux; this is done by using a $d-q$ rotating reference frame synchronously with the rotor flux space vector. The $d$-axis is then aligned with the rotor flux space vector [25]. Under this condition we get:

$$
\phi_{r q}=0, \phi_{r}=\phi_{r d}
$$

So, we can write :

$$
T_{e m}=\frac{p L_{m}}{L_{r}}\left(\phi_{r d} \cdot i_{s q}\right)
$$

For the direct rotor flux orientation (DFOC) of DFIM, accurate knowledge of the magnitude and position of the rotor flux vector is necessary. The flux estimator can be obtained by the following equations, [26]:

$$
\phi_{r}=\sqrt{\phi_{r \alpha}{ }^{2}+\varphi_{r \beta}{ }^{2}} \text { and } \theta_{s}=\tan ^{-1}\left(\frac{\phi_{r \beta}}{\phi_{r \alpha}}\right)
$$

\subsection{Sliding Mode Speed Control}

A Sliding Mode Controller (SMC) is a Variable Structure Controller (VSC). SMC method is a kind of robust control technique which is extensively utilized in nonlinear systems where parameter uncertainties exist. Basically, a VSC includes several different continuous functions that can map plant state to a control surface, whereas switching among different functions is determined by plant state represented by a switching function [27].

Speed adjustment is done by controlling the stator current $I_{s q}$.

So, the command law can be expressed as:

$$
I_{s q}^{r e f}=I_{s q}^{e q}+I_{s q}^{n}
$$

The expression of the speed control surface has the form:

$$
S(\omega)=\omega_{\text {ref }}-\omega
$$

The derivative of the surface is

$$
\dot{S}(\omega)=\dot{\omega}_{\text {ref }}-\dot{\omega}
$$

Then the mechanical equation equal to:

$$
\dot{\omega}=\frac{P \cdot L_{m}}{J \cdot L_{r}}\left(I_{s q} \cdot \varphi_{r d}^{r e f}\right)-\frac{p}{J} C_{r}-\frac{f}{J} \omega
$$

By replacing the mechanical equation in the equation of the switching surface, the derivative of the surface becomes:

$$
\dot{S}(\omega)=\dot{\omega}_{\text {ref }}-\left(\frac{P \cdot L_{m}}{J \cdot L_{r}}\left(I_{s q} \cdot \varphi_{r d}^{r e f}\right)-\frac{p}{J} C_{r}-\frac{f}{J} \omega\right)
$$

By replacing the current $I_{s q}$ by the current $I_{s q}^{r e f}=I_{s q}^{e q}+I_{s q}^{n}$, it is found that the command appears explicitly in the derivative of the surface, the latter will be written in the following form:

$$
\dot{S}(\omega)=\dot{\omega}_{r e f}-\left(\frac{P \cdot L_{m} \cdot \varphi_{r d}^{r e f}}{J \cdot L_{r}} I_{s q}^{e q}+\frac{P \cdot L_{m} \cdot \varphi_{r d}^{r e f}}{J \cdot L_{r}} I_{s q}^{n}-\frac{p}{J} C_{r}-\frac{f}{J} \omega\right)
$$

During the slip mode and in steady state, we have: 


$$
S(\omega)=0, \dot{S}(\omega)=0, I_{s q}^{n}=0
$$

From which one derives the magnitude of equivalent command, $I_{s q}^{e q}$ is written:

$$
I_{s q}^{e q}=\frac{J \cdot L_{r}}{P . L_{m} \cdot \varphi_{r d}^{r e f}}\left(\dot{\omega}_{r e f}+\frac{P}{J} C_{r}+\frac{f}{J} \omega\right)
$$

During the convergence mode, condition $\dot{V}(\omega)=S(\omega) . \dot{S}(\omega)<0$ must be verified. By replacing the expression of the equivalent command in the expression of the derivative of the surface, we obtain:

$$
\dot{S}(\omega)=-\frac{P \cdot L_{m} \cdot \varphi_{r d}^{r e f}}{J \cdot L_{r}} I_{s q}^{n}
$$

In which $I_{s q}^{n}=K_{i_{s q}} \operatorname{sign}(S(\omega))$, the $K_{i_{s q}}$ constant must be positive.

\section{SLIDING MODE FLUX OBSERVER DESIGN}

The objective of the sliding mode flux observer (SMFO) is to reconstruct the stator currents and rotor flux components and use them for speed estimation.

Based on the equations of the stator currents and the equations of the rotor flux of the machine in the fixed reference frame $(\alpha, \beta)$, we can write [28],[29]:

$$
\left\{\begin{array}{l}
\frac{d}{d t} i_{s \alpha}=-\lambda i_{s \alpha}+\omega_{s} i_{s \beta}+\frac{K}{T_{r}} \phi_{r \alpha}+\omega \cdot K \phi_{r \beta}+\frac{1}{\sigma L_{s}} v_{s \alpha}-K v_{r \alpha} \\
\frac{d}{d t} i_{s \beta}=-\omega_{s} i_{s \beta}-\lambda i_{s \beta}-\omega \cdot K \phi_{r \alpha}+\frac{K}{T_{r}} \phi_{r \beta}+\frac{1}{\sigma L_{s}} v_{s \beta}-K v_{r \beta} \\
\frac{d}{d t} \phi_{r \alpha}=\frac{L_{m}}{T_{r}} i_{s \alpha}-\frac{1}{T_{r}} \phi_{r \alpha}+\omega \cdot \phi_{r \beta}+v_{r \alpha} \\
\frac{d}{d t} \phi_{r \beta}=\frac{L_{m}}{T_{r}} i_{s \beta}-\omega \cdot \phi_{r \alpha}-\frac{1}{T_{r}} \phi_{r \beta}+v_{r \beta}
\end{array}\right.
$$

With:

$$
T_{r}=\frac{L_{r}}{R_{r}} ; T_{s}=\frac{L_{s}}{R_{s}} ; \lambda=\frac{1}{\sigma . T_{r}} ; K=\frac{L_{m}}{\sigma L_{s .} L_{r}} ; \quad \sigma=1-\frac{L_{m}^{2}}{L_{s} L_{r}}
$$

Let's $\hat{x}_{1}, \hat{x}_{2}, \hat{x}_{3}, \hat{x}_{4}$ be the estimates of the $x_{1}, x_{2}, x_{3}, x_{4}$ respectively which are the state variables of $i_{s \alpha}, i_{s \beta}, \phi_{r \alpha}, \phi_{r \beta}$. The observer is only a copy of the original system to which one adds the control gains with the terms of commutation; thus, [30]:

$$
\left\{\begin{array}{l}
\dot{\hat{x}}_{1}=-\lambda \hat{x}_{1}+\omega_{s} \hat{x}_{2}+\frac{K}{T_{r}} \hat{x}_{3}+\omega \cdot K \hat{x}_{4}+\frac{1}{\sigma L_{s}} v_{s \alpha}-K v_{r \alpha}+g_{1} I_{s} \\
\dot{\hat{x}}_{2}=-\omega_{s} \hat{x}_{2}-\lambda \hat{x}_{2}-\omega \cdot K \hat{x}_{3}+\frac{K}{T_{r}} \hat{x}_{4}+\frac{1}{\sigma L_{s}} v_{s \beta}-K v_{r \beta}+g_{2} I_{s} \\
\dot{\hat{x}}_{3}=\frac{L_{m}}{T_{r}} \hat{x}_{1}-\frac{1}{T_{r}} \hat{x}_{3}+\omega \cdot \hat{x}_{4}+v_{r \alpha}+g_{3} I_{s} \\
\dot{\hat{x}}_{4}=\frac{L_{m}}{T_{r}} \hat{x}_{2}-\omega \cdot \hat{x}_{3}-\frac{1}{T_{r}} \hat{x}_{4}+v_{r \beta}+g_{4} I_{s}
\end{array}\right.
$$

Where $g_{1}, g_{2}, g_{3}, g_{4}$ are observer gains, $g_{j}=\left[\begin{array}{ll}g_{j 1} & g_{j 2}\end{array}\right]$ for $j \in\{1,2,3,4\}$

The vector $I_{s}$ is given by:

$$
I_{s}=\left[\begin{array}{l}
\operatorname{sign}\left(S_{1}\right) \\
\operatorname{sign}\left(S_{2}\right)
\end{array}\right]
$$

With

$$
S_{o b}=\left[\begin{array}{l}
S_{1} \\
S_{2}
\end{array}\right]=\Gamma\left[\begin{array}{l}
x_{1}-\hat{x}_{1} \\
x_{2}-\hat{x}_{2}
\end{array}\right]=\Gamma\left[\begin{array}{c}
i_{s \alpha}-\hat{i}_{s \alpha} \\
i_{s \beta}-\hat{i}_{s \beta}
\end{array}\right]
$$

The dynamics of estimation error are given by: 


$$
\begin{aligned}
& \dot{e}_{1}=\frac{K}{T_{r}} e_{3}+\omega K e_{4}-g_{1} I_{s} \\
& \dot{e}_{2}=\frac{K}{T_{r}} e_{4}-\omega K e_{3}-g_{2} I_{s} \\
& \dot{e}_{3}=-\frac{1}{T_{r}} e_{3}-\omega e_{4}-g_{3} I_{s} \\
& \dot{e}_{4}=-\frac{1}{T_{r}} e_{4}+\omega e_{3}-g_{4} I_{s}
\end{aligned}
$$

\section{- Estimation of speed by sliding mode observer}

Consider the error dynamics of the flux observer given by equation (44), this equation can be rewritten in the following form, [31]:

$$
\dot{e}(\omega)=A(\omega) \cdot e+C_{g}(\omega) \cdot I_{s g}(\omega)
$$

With

$$
\dot{e}(\omega)=\left[\begin{array}{c}
\dot{e}_{1} \\
\dot{e}_{2} \\
\dot{e}_{3} \\
\dot{e}_{4}
\end{array}\right] ; A(\omega)=\left[\begin{array}{cccc}
0 & 0 & \frac{K}{T_{r}} & K . \omega \\
0 & 0 & -K . \omega & \frac{K}{T_{r}} \\
0 & 0 & \frac{-1}{T_{r}} & -\omega \\
0 & 0 & \omega & \frac{-1}{T_{r}}
\end{array}\right] ; G_{g}(\omega)=\left[\begin{array}{cc}
\frac{K}{T_{r}} \cdot \delta_{1} & \frac{K}{T_{r}} \cdot \omega \cdot \delta_{2} \\
-\frac{K}{T_{r}} \cdot \omega \cdot \delta_{1} & \frac{K}{T_{r}} \cdot \delta_{2} \\
\left(q_{1}-\frac{1}{T_{r}}\right) \cdot \delta_{1} & -\omega \cdot \delta_{2} \\
\omega \cdot \delta_{1} & \left(q_{2}-\frac{1}{T_{r}}\right) \cdot \delta_{2}
\end{array}\right]
$$

Suppose now that the rotor speed $\omega$ is replaced by its estimated $\hat{\omega}=\omega-\Delta \omega$, so:

With

$$
\dot{e}(\widehat{\omega})=A(\widehat{\omega}) \cdot e+G_{g}(\widehat{\omega}) \cdot I_{s g}(\widehat{\omega})
$$

$$
\begin{aligned}
A(\hat{\omega}) & =A(\omega)+\Delta \Omega \\
G_{g}(\hat{\omega}) & =G_{g}(\omega)+\Delta G_{g} \\
I_{s g} & =\operatorname{sign}\left[\begin{array}{c}
\frac{K}{T_{r}} \cdot e_{2} \cdot \Delta \omega \\
S_{1}+\frac{K}{\beta} \\
S_{2}+\frac{\frac{T_{r}}{\beta} e_{1} \cdot \Delta \omega}{\beta}
\end{array}\right]
\end{aligned}
$$

And

$$
\Delta A=\left[\begin{array}{cccc}
0 & 0 & 0 & -K . \Delta \omega \\
0 & 0 & K . \Delta \omega & 0 \\
0 & 0 & 0 & \Delta \omega \\
0 & 0 & -\Delta \omega & 0
\end{array}\right] \Delta G_{g}=\left[\begin{array}{cc}
0 & \frac{K}{T_{r}} \cdot \Delta \omega \cdot \delta_{2} \\
-\frac{K}{T_{r}} \cdot \Delta \omega \cdot \delta_{1} & 0 \\
0 & \Delta \omega \cdot \delta_{2} \\
-\Delta \omega \cdot \delta_{1} & 0
\end{array}\right]
$$

The idea is to apply the criterion of stability of lyapunov to see the convergence of the error towards zero, for this one chooses the function of lyapunov of the following form, [30]:

$$
v=\frac{1}{2} e \cdot e^{T}+\frac{1}{2 \lambda}(\Delta \omega)^{2}
$$

The derivative of equation (49) with respect to time is:

$$
\dot{v}=e^{T} \cdot \dot{e}(\widehat{\omega})+\frac{1}{\lambda} \Delta \omega \cdot \dot{\hat{\omega}}
$$

Let us replace $\dot{e}(\widehat{\omega})$ by its value, then equation (50) becomes:

$$
\dot{v}=e^{T}\left\{(A(\omega)+\Delta A) \cdot e-\left(G_{g}+\Delta G_{g}\right) \cdot I_{s g}(\omega)\right\}+e^{T} \cdot G_{g} \cdot I_{s g}-e^{T} \cdot G_{g} \cdot I_{s g}+\frac{1}{\lambda} \Delta \omega
$$

An adaptation law for the rotor speed is deduced:

$$
\begin{aligned}
& \dot{\hat{\omega}}=\lambda \cdot K \cdot p \cdot\left(e_{1} \cdot \hat{x}_{4}-e_{2} \cdot \hat{x}_{3}\right) \\
& \dot{\hat{\omega}}=\lambda \cdot K \cdot p \cdot\left(\left(i_{s \alpha}-\hat{\imath}_{s \alpha}\right) \cdot \hat{\varphi}_{r \beta}-\left(i_{s \beta}-\hat{\imath}_{s \beta}\right) \cdot \hat{\varphi}_{r \alpha}\right)
\end{aligned}
$$




\section{RESULTS AND DISCUSSION}

For the validation of the proposed DPC strategy, the system has been modelled and built in MATLAB/SIMULINK software environment and tested under various conditions.

The control of three phase rectifier aims to maintain a constant dc-link voltage, and it is controlled using DPC_VF method based on virtual flux estimator with vector modulation (SVM).

The main electrical parameters of the system are given in table1.

Table 1. Parameters of the power circuit

\begin{tabular}{|c|c|c|c|c|c|}
\hline Line resistance & $\begin{array}{c}\text { Line } \\
\text { inductance }\end{array}$ & $\begin{array}{l}\text { Load } \\
\text { resistance }\end{array}$ & $\begin{array}{l}\text { Source voltage } \\
\text { frequency }\end{array}$ & $\begin{array}{c}\text { Peak } \\
\text { amplitude of } \\
\text { line voltage }\end{array}$ & $\begin{array}{c}\text { DC-Voltage } \\
\text { Reference }\end{array}$ \\
\hline$R=0.25 \Omega$ & $L=10 \mathrm{mH}$ & $R_{c h}=100 \Omega$ & $50 \mathrm{~Hz}$ & $\sqrt{2} 220 \mathrm{~V}$ & $V_{d c}=600 \mathrm{~V}$ \\
\hline
\end{tabular}

The simulation results obtained are illustrated in Figures 4-9 below:

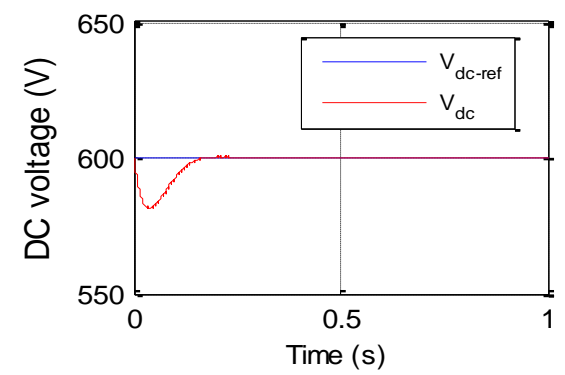

Figure 4. DC output voltage

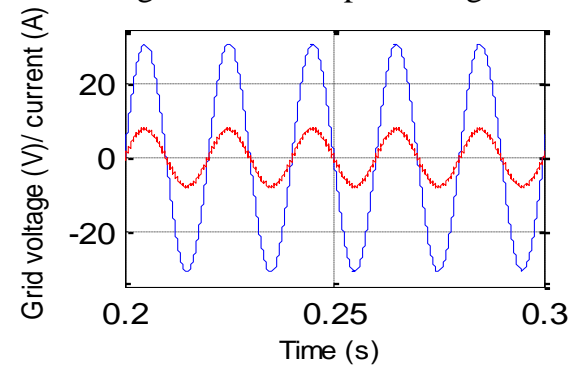

Figure 6. Voltage and current waveforms of phase 'a'

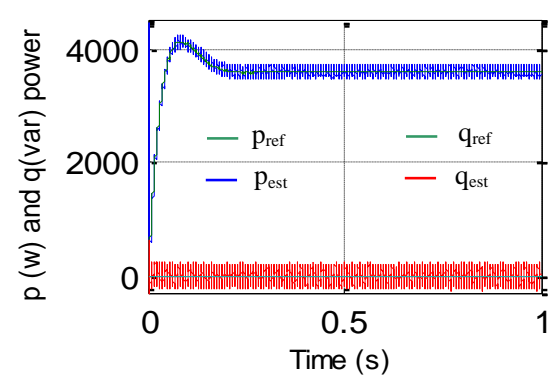

Figure 5. Active and reactive powers

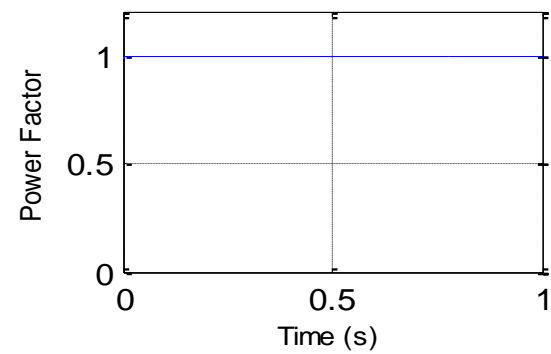

Figure 7. Power Factor

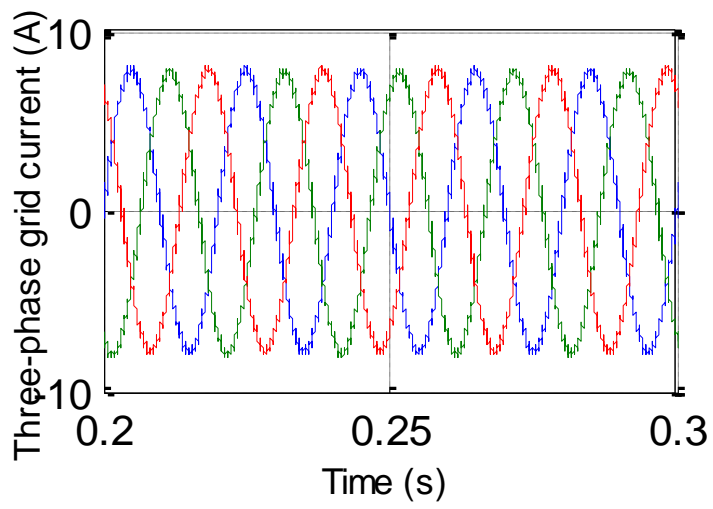

Figure 8. Zoom of line current 


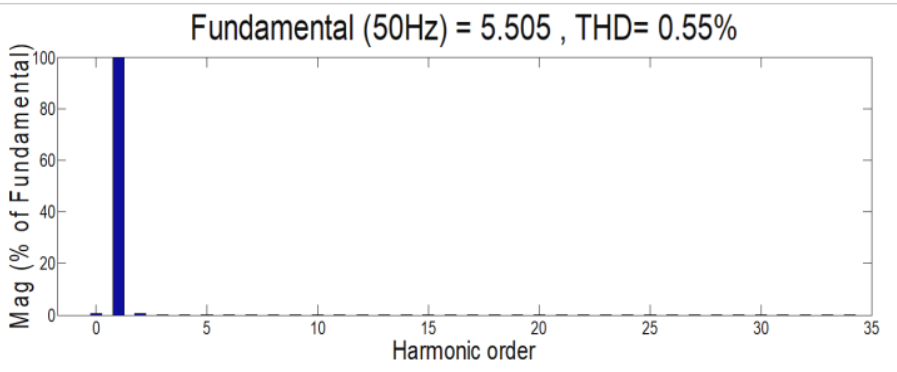

Figure 9. Line current harmonics spectrum

From Figure 4, we clearly see a good tracking at steady state between the DC voltage and the reference one. The active and reactive powers estimated follow perfectly their references (Figure 5). The line voltage and current are in phase and the power factor is almost unity (Figures 6 and 7). The line current is substantially sinusoidal with a low harmonic distortion ratio THD which equals to $0.55 \%$ (Figures 8 and 9).

To test the robustness of the proposed technique (VFDPC_SVM) and in order to show these dynamic performances, a variation of the reference DC voltage from $600 \mathrm{~V}$ to $700 \mathrm{~V}$ has been carried out. In this case; we notice that the active power and the line current increase starting from $0.5 \mathrm{~s}$ and then it stabilizes perfectly at steady state while the reactive power remains fixed to its reference. This is due to the good regulation of the DC voltage.

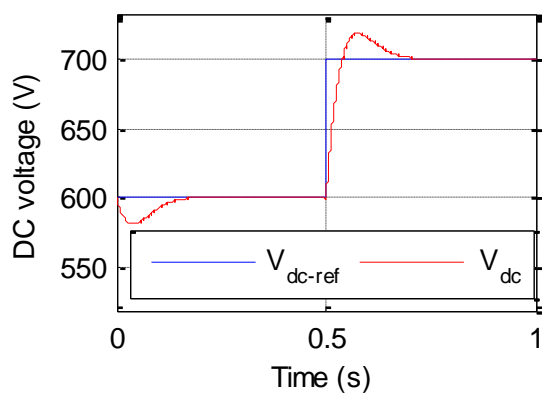

Figure 10. DC output voltage

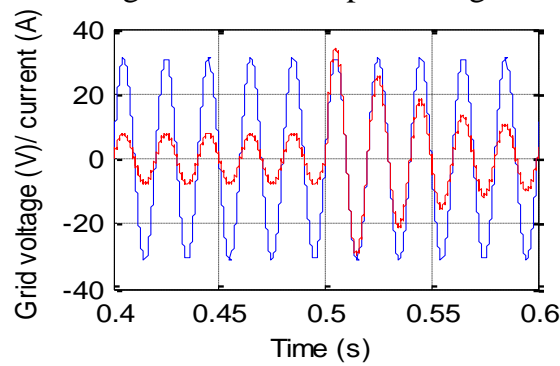

Figure 12. Voltage and current waveforms of phase 'a'

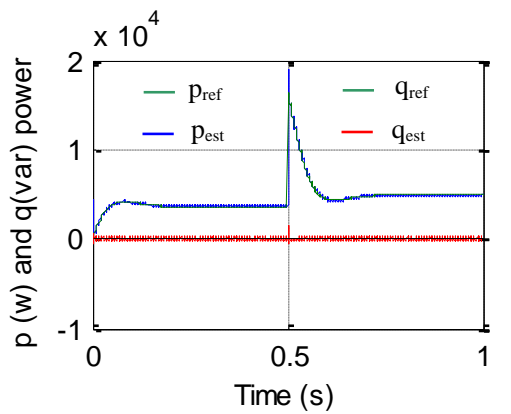

Figure 11. Active and reactive powers

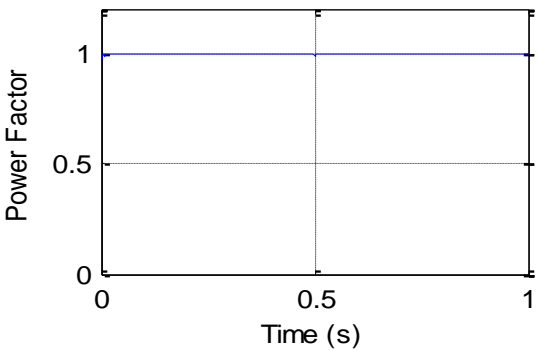

Figure 13. Power Factor

The objective of this work is to provide a robust sensorless vector control of a doubly fed induction motor associated with a sliding mode observer (Figure 14). The power system consists of a three-level inverter, its source of continuous energy is obtained by a PWM rectifier. in this work, we propose a robust speed adjustment technique based on the sliding mode controller. 


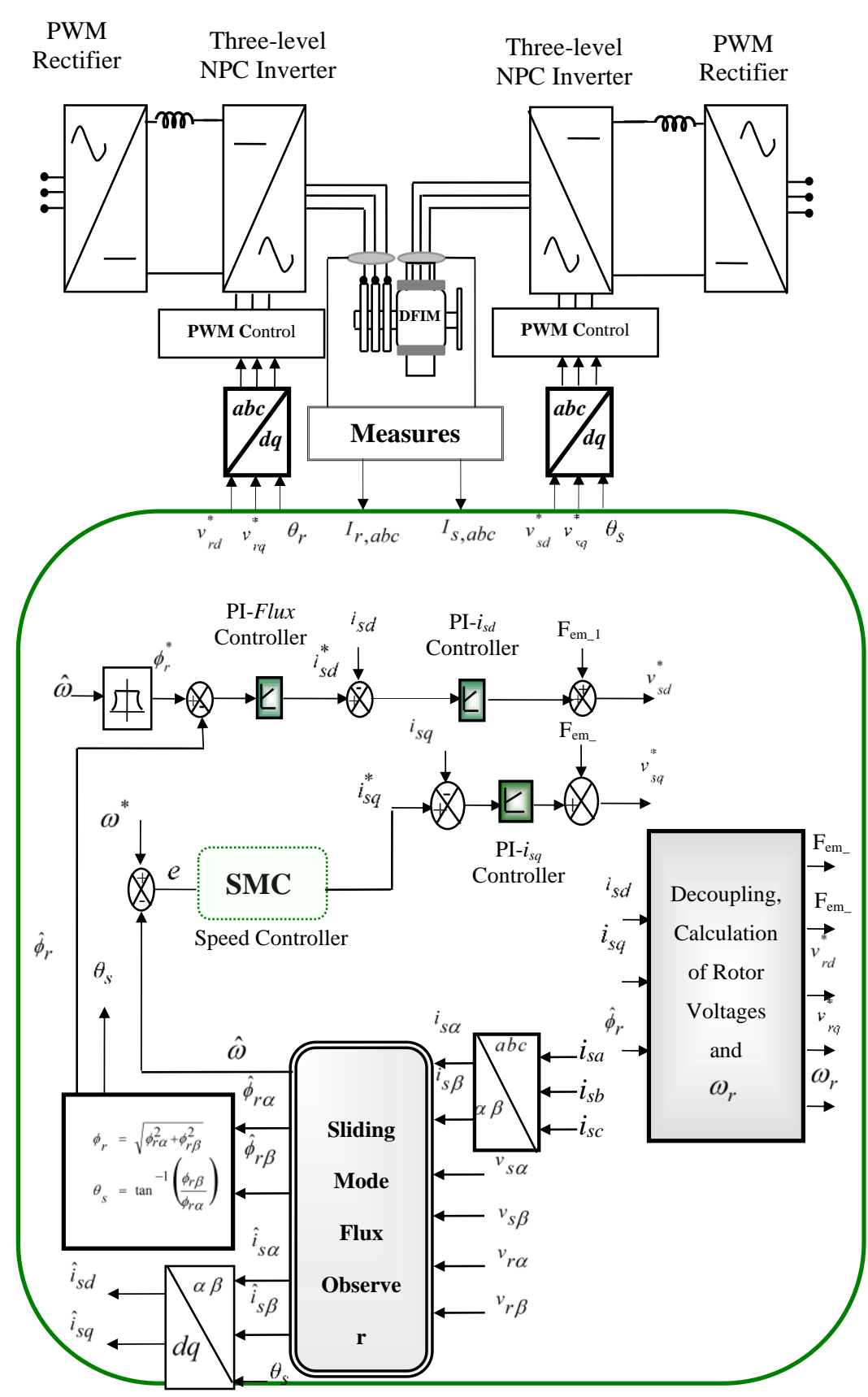

Figure 14. Block diagram of sensorless direct vector control of DFIM using a sliding mode observer

In order to evaluate the performance of the sliding mode estimation algorithm and therefore the overall drive system performance, we subjected our system to simulation tests for direct oriented rotor flux (Figure $15)$.

To test the static and dynamic sliding mode observer performance, DFIM fed by two voltage inverters (Three-level NPC Inverter) and DPC-VF-SVM is used. This test concerns a no-load starting of the motor with a reference speed $\omega_{\text {ref }}=250 \mathrm{rad} / \mathrm{s}$ and then a load disturbance torque $(10 \mathrm{~N} . \mathrm{m})$ is suddenly applied between $1 \mathrm{sec}$ and $2 \mathrm{sec}$, followed by a consign inversion $(-250 \mathrm{rad} / \mathrm{s})$ at $2.5 \mathrm{~s}$. This test has objection to the study of controller behaviors in tracking and regulation. 


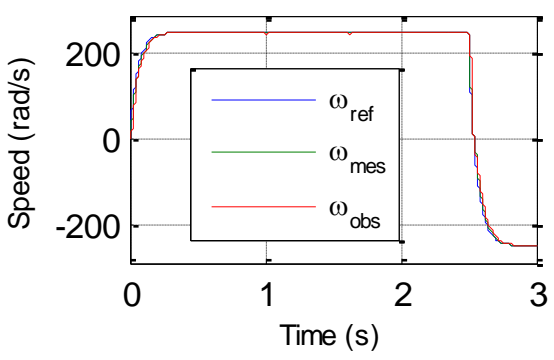

a

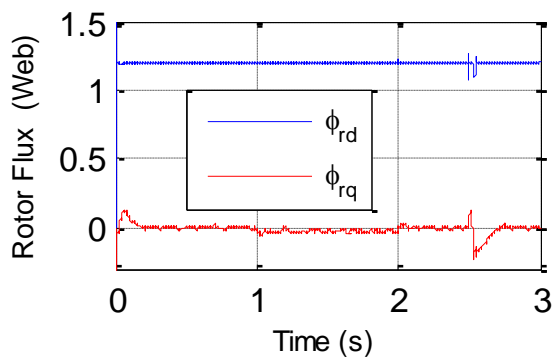

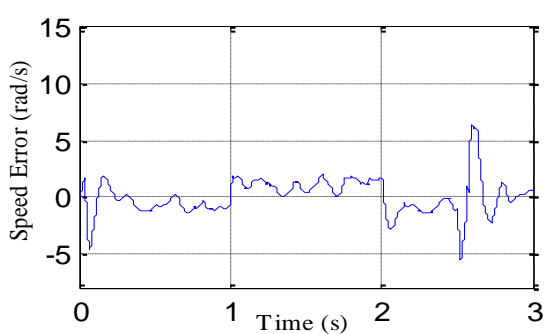

b

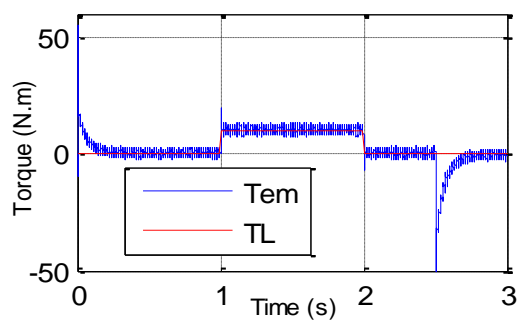

d

Figure 15. Dynamic responses for proposed sensorless control drives of DFIM using 3 level NPC inverter and DPC-VF-SVM

The simulation results show a good performance (speed, stability and precision). The estimated speed tracks perfectly the real speed with a static error which equals almost to zero. We also notice that there is good sensitivity to load disturbances as observed, with a relatively low rejection time.

We clearly see again an excellent orientation of the rotor flux on the direct axis, during the changes of the set points, and in particular during the inversion of rotation. However, the change of direction of the torque does not degrade the orientation of the fluxes.

\section{CONCLUSION}

In this paper, in the first part a robust DPC control was presented, based on virtual flux estimator for a better control of the PWM rectifier. The effectiveness of this control was obtained by correcting the active and reactive power at the same time andit can be found that its are independent of each other. Moreover, the result shows that the THD of the source current is $0.55 \%$ and this control ensures a power factor equal to unity. Application of the three-level inverter fed by PWM rectifier system as DC source input for sensorless control for a doubly fed induction machine operating in motor mode is presented in the second part and to solve different drawbacks of the PI speed controller, a sliding mode controller is proposed.

The features of the proposed method can be summarized as follows: good speed estimate, good dynamic control of flux and torque, sinusoidal stator currents waveform, a unit power factor and low THD. Sliding mode controller provides effective improvements and ensures a good regulation of speed whatever the operating ranges studied and load disturbances.

\section{APPENDIX}

Table 2. DFIM Parameters

\begin{tabular}{lc}
\hline \multicolumn{1}{c}{ Item } & Data \\
\hline DSIM Mechanical Power & $1.5 \mathrm{Kw}$ \\
Nominal speed & $1450 \mathrm{rpm}$ \\
Pole pairs number & 2 \\
Stator resistance & $1.68 \Omega$ \\
Rotor resistance & $1.75 \Omega$ \\
Stator self inductance & $295 \mathrm{mH}$ \\
\hline
\end{tabular}

\begin{tabular}{lc}
\hline \multicolumn{1}{c}{ Item } & Data \\
\hline Rotor self inductance & $104 \mathrm{mH}$ \\
Mutual inductance & $165 \mathrm{mH}$ \\
Moment of inertia & $0.01 \mathrm{~kg} \cdot \mathrm{m}^{2}$ \\
friction coefficient & $0.0027 \mathrm{~kg} \cdot \mathrm{m}^{2} / \mathrm{s}$ \\
Nominal Frequency & $50 \mathrm{~Hz}$
\end{tabular}

\section{REFERENCES}

[1] M. Malinowski, M. Jasinski, and M. P. Kazmierkowski, " Simple Direct Power Control of Three-Phase PWM Rectifier Using Space-Vector Modulation (DPC-SVM)," IEEE Transactions on Industrial Electronics, Vol. 51, No. 2, 2004. 
[2] D. Cherifi and Y. Miloud, "Performance analysis of adaptive fuzzy sliding mode for nonlinear control of the doubly fed induction motor," Indonesian Journal of Electrical Engineering and Informatics (IJEEI), Vol. 6, No. 4, pp. 436-447, 2018.

[3] C. Navaneethakkannan and M. Sudha, "Comparison of Conventional \& PID Tuning of Sliding Mode Fuzzy Controller for BLDC Motor Drives," In: Proc. of International Conference on Computer Communication and Informatics (ICCCI-2013), Coimbatore, INDIA, Jan. 04 - 06, 2013.

[4] K. Loukal and L. Benalia, "Type-2 Fuzzy logic controller of a doubly fed induction machine", Hindawi Publishing Corporation, Advances in Fuzzy Systems, pp. 1-10, 2016.

[5] M. Zerikat, S. Chekroun, and A. Mechernene, " A robust MRAS-sensorless scheme based rotor and stator resistances estimation of a direct vector controlled induction motor drive," IEEE, pp.151-156, 2011.

[6] S. K. Sahu, and D.D. Neema, "A robust speed sensorless vector control of multilevel inverter fed induction motor using particle swarm optimization," International Journal of Innovative Research in Electrical, Electronics, Instrumentation and Control Engineering, Vol. 3, Issue 1, pp. 23-32, 2015.

[7] R. Gunabalan and V. Subbiah, " Speed sensorless vector control of induction motor drive with PI and fuzzy controller," International Journal of Power Electronics and Drive System (IJPEDS), Vol. 5, No. 3, pp. 315-325, 2015.

[8] E. Avci and M. Ucar, "Analysis and design of grid-connected 3-phase 3-level AT-NPC inverter for lowvoltage applications," Turkish Journal of Electrical Engineering \& Computer Sciences, pp. 2464 - 2478 , 2017.

[9] P. S. Chandrashekhar, "Neutral Point Clamped (Npc) Type Multilevel Inverter," International Journal of Scientific \& Technology Research, Volume 5, Issue 09, 2016.

[10] A. Rahab, F.Senani, and H. Benalla, "Direct power control of three phase PWM rectifier based DSOGIVF estimator for No-Ideal line voltages conditions," Journal of Engineering Research and Application, Vol. 8, Issue 1, pp.10-18, 2018.

[11] J. Lamterkati, M. Khafallah, and L. Ouboubker, " A New DPC for Three-phase PWM rectifier with unity power factor operation", International Journal of Advanced Research in Electrical, Electronics and Instrumentation Engineering, Vol. 3, Issue 4, pp. 8273- 8285, 2014.

[12] A. Baktash and A. Vahedi, "New switching table for improved direct power control of three-phase PWM rectifier," Australian Journal of Electrical and Electronics Engineering, Vol 5 No 2, pp. 161-167, 2009.

[13] A. Bouafia, F. Krim, and J. P. Gaubert, "Design and implementation of high performance direct power control of three-phase PWM rectifier, via fuzzy and PI controller for output voltage regulation," Energy Conversion and Management, pp. 6-13, 2009.

[14] L. Xiong, P. Li, Hao Li, and J. Wang, "Sliding Mode Control of DFIG Wind Turbines with a Fast Exponential Reaching Law", Energies 2017.

[15] A. S. Pabbewar and M. Kowsalya, "Three Level Neutral Point Clamped Inverter using Space Vector Modulation with Proportional Resonant Controller," Energy Procedia, pp. 286 - 291, 2016.

[16] M. Kashif, Z. Fang, S. Gautam, Y. Li, and A. Syed, " A Study of three-level neutral point clamped inverter topology," TELKOMNIKA Indonesian Journal of Electrical Engineering, Vol. 12, No. 8, pp. 5999 - 6008, 2014.

[17] F. Sebaaly, H. Y. Kanaan, and N. Moubayed, "Three-Level Neutral-Point-Clamped Inverters in Transformerless PV Systems - State of the Art," IEEE, 2014.

[18] J. Huang, A. Zhang, H. Zhang, and J. Wang, "A Novel Fuzzy-Based and Voltage-Oriented Direct Power Control Strategy for Rectifier," IEEE, 2011.

[19] M. Malinowski, M. Jasinski, and M. P. Kazmierkowski "Simple Direct Power Control of Three-Phase PWM Rectifier Using Space-Vector Modulation (DPC-SVM)," IEEE Transactions on Industrial Electronics, Vol. 51, No. 2, 2004.

[20] M. A. Razali and M.A. Rahman "Performance Analysis of Three-Phase PWM Rectifier Using Direct Power Control," IEEE International Electric Machines \& Drives Conference (IEMDC), pp. 16033-1605, 2011.

[21] Y. Zhang, Z. Li, Y. Zhang, W. Xie, Z. Piao, and C. Hu, "Performance improvement of direct power control of pwm rectifier with simple calculation," Power Electronics, IEEE Transactions on Industry Applications, vol. 28, no. 7, pp. 3428-3437, 2013. 
[22] M. Malinowski, M. P. Kazmierkowski, S. Hansen, F. Blaabjerg, and G. D. Marques, "Virtual-Flux-Based Direct Power Control of Three-Phase PWM Rectifiers," IEEE Transactions on Industry Applications, Vol. 37, No. 4, 2001.

[23] A.Fekik, H.Denoun, N.Benamrouche, N. Benyahia, A. Badji, and M. Zaouia, "Comparative Analysis of Direct Power Control and Direct power control with space vector modulation of PWM rectifier," In: Proc. of International Conference on Control Engineering \& Infonnation Technology (CElT-2016) Tunisia, Hammamet- December, 16-18, 2016.

[24] Blaschke E. "The principle of field orientation as applied to the new trans vector closed-loop control system for rotating field machine", Siemens Review; Vol. 34 .pp. 217-220, 1972.

[25] M. Abid, A. Aissaoui, and H. Bounoua, "Sliding mode application in speed and flux control of an induction machine," Journal of Electrical and Electronics Engineering, vol.6, no.2, pp.197-204, 2006.

[26] J. B. Alaya, A. Khedher, and M. F. Mimouni, "Speed-Sensorless DFIG Wind Drive Based on DTC Using Sliding Mode Rotor Flux Observer," International Journal of Renewable Energy Research, Vol.2, No.4, 2012.

[27] H. Rahali, S. Zeghlache, L. Benalia, and N. Layadi, "Sliding mode control based on backstepping approach for a double star induction motor (DSIM)". AMSE Journals, Advances in Modelling and Analysis C, Vol. 73, No. 4, pp. 150-157, 2018.

[28] M. Ghanes and G. Zheng," On Sensorless Induction Motor Drives: Sliding Mode Observer and Output Feedback Controller, " IEEE Transactions on Industrial Electronics, Vol. XX, No. YY, 2009.

[29] H. Kim, J. Son, and J. Lee, "A High-Speed Sliding-Mode Observer for the Sensorless Speed Control of a PMSM," IEEE Transactions on Industrial Electronics, Vol. 58, No. 9, 2011.

[30] F. Mellah, M. Chenafa, A. Bouhenna, and A. Mansouri, "Passivity Control with sliding mode observer of induction motor," Przegląd Elektrotechniczny (Electrical Review), 2011.

[31] C. B. Regaya, A. Zaafouri, and A. Chaari, "A New Sliding Mode Speed Observer of Electric Motor Drive Based on Fuzzy-Logic", Acta Polytechnica Hungarica. Vol. 11, No. 3, 2014. 